\title{
A model of perceptual discrimination under sequential sensory evidence
}

\author{
Etienne Hugues ${ }^{1 *}$, Carlos Stein Naves de Brito ${ }^{2}$, Wulfram Gerstner ${ }^{2}$, Ranulfo Romo ${ }^{3}$, Gustavo Deco ${ }^{1,4}$ \\ From Twenty Second Annual Computational Neuroscience Meeting: CNS*2013 \\ Paris, France. 13-18 July 2013
}

Perceptual discrimination may be interpreted as a decision between alternatives based on available sensory evidence. In many experiments, the different alternatives are encoded by quite distinct neuronal groups. In this case, proposed neural models consider that the decision results from the competition between decision-specific neuronal groups, each of these integrating distinct sensory evidence [1]. Alternatively, evidence may be presented in a sequential manner, and the different stimuli may be encoded by the same neuronal group, as exemplified by experiments where monkeys are engaged in a vibrotactile discrimination task [2]. To achieve discrimination in this case, the nervous system needs to keep a trace of the previously presented stimuli. How the correct discrimination can be learned and implemented is poorly understood.

To address these questions, we use a modeling approach. We concentrate on the particular case of the vibrotactile discrimination task on which experimental insight has been accumulated over the last years [2]. The partial differential (PD) neurons in monkey area VPC, encoding both sequentially presented vibrotactile stimuli (with frequencies $f_{1}$ and $f_{2}$ ) by keeping the memory of the first one during a delay period, have been reproduced in a spiking neuron network model with short-term facilitating synapses [3]. We want to explore how these PD neurons may be used to discriminate between both stimuli configurations: $f_{1}>f_{2}$ or $f_{1}<f_{2}$. Based on the experimental evidence, we model a heterogeneous PD neuronal population, encoding both frequencies in multiple ways. Downstream to the first network, we add a competitionbased decision making spiking neuron network [1]. To obtain the desired neural dynamics of the coupled

\footnotetext{
* Correspondence: etienne.hugues@upf.edu

${ }^{1}$ Center of Brain and Cognition, Department of Information and Communication Technologies, Universitat Pompeu Fabra, Barcelona, 08018, Spain

Full list of author information is available at the end of the article
}

two-networks model, we choose the model parameters using a simplified mean-field description of the model. To make the best possible decisions, the strengths of the synapses projecting from the PD neurons to the decision neurons must be learned. Based on reinforcement learning theory, we use a learning rule which maximizes reward. It depends on a reward prediction error, evaluated using the reward history. We instantiate this rule using a reward based spike-timing-dependent plasticity [4]. Learning takes place after the second stimulus presentation. We find that the task can be efficiently learned for any number of PD neuron types, even when their stimulus encoding function is nonlinear and noisy.

In conclusion, the present biologically plausible twonetworks model is able to solve a perceptual discrimination task under sequential sensory evidence.

\section{Acknowledgements \\ This work has been supported by the European Community's Seventh Framework Program (grant agreement 269921, BrainScaleS).}

\section{Author details}

${ }^{1}$ Center of Brain and Cognition, Department of Information and Communication Technologies, Universitat Pompeu Fabra, Barcelona, 08018, Spain. ${ }^{2}$ School of Computer and Communication Sciences and Brain Mind Institute, School of Life Sciences, Ecole Polytechnique Fédérale de Lausanne, Lausanne, 1015, Switzerland. ${ }^{3}$ Instituto de Fisiología Celular-Neurociencias, Universidad Nacional Autónoma de México, México, 04510, Mexico. ${ }^{4}$ Institució Catalana de Recerca i Estudis Avançats, Universitat Pompeu Fabra, Barcelona, 08018, Spain.

Published: 8 July 2013

\section{References}

1. Wang $X$-J: Probabilistic decision making by slow reverberation in cortical circuits. Neuron 2002, 36:955-968.

2. Hernández $A$, Nácher $V$, Luna $R$, Zainos $A$, Lemus $L$, Alvarez $M$, Vázquez $Y$, Camarillo L, Romo R: Decoding a perceptual decision process across cortex. Neuron 2010, 66:300-314.

3. Deco G, Rolls ET, Romo R: Synaptic dynamics and decision making. Proc Natl Acad Sci USA 2010, 107:7545-7549. 
4. Frémeaux N, Sprekeler H, Gerstner W: Functional requirements for rewardmodulated spike-timing-dependent plasticity. I Neurosci 2010, 30(40):13326-13337.

doi:10.1186/1471-2202-14-S1-P102

Cite this article as: Hugues et al: A model of perceptual discrimination under sequential sensory evidence. BMC Neuroscience 2013 14(Suppl 1): P102.

Submit your next manuscript to BioMed Central and take full advantage of:

- Convenient online submission

- Thorough peer review

- No space constraints or color figure charges

- Immediate publication on acceptance

- Inclusion in PubMed, CAS, Scopus and Google Scholar

- Research which is freely available for redistribution

Submit your manuscript at www.biomedcentral.com/submit
C Biomed Central 